\title{
Aumento da Oferta e Redução de Impostos nos Serviços de Infra-estrutura na Economia Brasileira: Uma Abordagem de Equilíbrio Geral*
}

\author{
Maria Aparecida Silva Oliveira ${ }^{\dagger}$, Erly Cardoso Teixeira ${ }^{\ddagger}$
}

\author{
Contents: 1. Introdução; 2. Infra-estrutura nas Teorias do Crescimento; 3. Tributação e \\ Eficiência; 4. Modelo Analítico; 5. Resultados; 6. Conclusões; A. Tabelas. \\ Keywords: Infra-estrutura; Serviços; Impostos; Equilíbrio Geral. \\ JEL Code: D58; H30; H54.
}

A baixa qualidade da infra-estrutura e a elevada carga tributária que incide sobre esses setores oneram a utilização de seus serviços. O objetivo desta pesquisa é analisar os impactos do aumento na oferta de infraestrutura e da redução nos impostos sobre seus serviços na economia brasileira. Foi utilizado um Modelo Aplicado de Equilíbrio Geral. Essas políticas proporcionariam crescimento da atividade agregada e ganhos de competitividade. $O$ crescimento da renda e os ganhos de competitividade levariam ao crescimento das exportações; elevação na remuneração aos fatores, ocasionando elevação na renda das famílias e nos investimentos; e aumento na receita do governo e no PIB, além dos ganhos de utilidade pelos consumidores. Low quality of infrastructure and high tax burden on those sectors make more expensive their services. The purpose of this paper is to analyze the impacts of the increase in the supply of infrastructure services, and taxes reduction on those services on the Brazilian economy. A General Equilibrium Model was used to run the simulations. Those polices would increase sectors competitiveness and economic growth. Also, exports and factors remuneration would increase, causing elevation in the families' income and investments. Government tax collection, GDP, and consumer utility would increase in the scenarios where infrastructure service expansion and tax reduction are simulated.

\footnotetext{
* Os autores agradecem aos revisores anônimos da revista pelas sugestões e à CAPES pelo apoio financeiro.

${ }^{\dagger}$ Professora da Universidade Federal de São Carlos (UFSCar); Rod. João Leme dos Santos Km 110 SP-264, Bairro Itinga, Sorocaba-SP, CEP: 18052-780. E-mail: aparecidaoliveira@ufscar.br

‡Professor Titular Universidade Federal de Viçosa (UFV); 36570-000 - Viçosa-MG. E-mail: teixeira@ufv . br
} 


\section{INTRODUÇÃO}

As condições atuais da infra-estrutura no Brasil constituem um obstáculo à retomada do crescimento de forma sustentada. Grande parte dela, em muitos setores, encontra-se deteriorada ou obsoleta, o que implica redução na qualidade dos serviços e altos custos para os usuários ou para a sociedade. A pequena disponibilidade e a baixa qualidade desses serviços no país transmitem os seus efeitos por toda a economia, o que resulta em custos elevados, ineficiência e baixa competitividade, desestimulando o investimento e, assim, a geração de emprego e o crescimento.

De acordo com Ferreira (1996), o desafio posto à sociedade brasileira é, além de recuperar a parte da infra-estrutura deteriorada, ampliá-la para atender às necessidades atuais e futuras da economia. Essas necessidades têm surgido do aumento na demanda de serviços prestados por esse setor, que se deveu, sobretudo, ao crescimento das exportações e à expansão da fronteira agrícola (Martins, 2004). Entretanto, o aumento na demanda não tem sido acompanhado pelo crescimento de investimento público nesse setor.

Os investimentos nos setores de energia e de transporte reduziram-se em 75,87\% e 89,66\%, respectivamente, nos anos de 1980 a 1993 (Ferreira, 1996). De acordo com o Ministério do Planejamento, Orçamento e Gestão (Ministério do Planejamento, 2003), os gastos públicos com o setor elétrico reduziram $18,57 \%$, de 1995 a 2001 , e com o de transportes, $10,32 \%$.

A necessidade de melhorar o sistema de infra-estrutura no Brasil é justificada pela implementação de medidas que contribuam para a efetiva redução nos custos desses serviços. A diferença entre esses custos no Brasil e em países mais eficientes constitui parte do que se denomina Custo Brasil (Lima et al., 1997).

O setor elétrico está entre os que podem comprometer a viabilidade das atividades produtivas. A defasagem de investimentos em energia elétrica é apontada como o principal fator que provocou desequilíbrios entre demanda e oferta por esse serviço, o que levou ao racionamento que afetou o país em 2001. É necessária a garantia da oferta de energia a preços adequados para impulsionar o crescimento econômico (Ministério do Planejamento, 2003).

Além disso, a atual degradação do setor de transportes do país, aliada aos reduzidos investimentos feitos nesse setor, insuficientes até mesmo para reposição, torna-o inadequado e ineficiente, o que prejudica o desempenho da economia e a competitividade das empresas. A deficiência do setor rodoviário nacional é prejudicial à economia, pois, por ele, são transportados mais de $60 \%$ das cargas e $95 \%$ dos passageiros (MPOG, op cit.).

O sistema de armazenagem e os procedimentos aduaneiros restringem o escoamento da produção e limitam as exportações e importações. A deficiência dos portos brasileiros prejudica sobremaneira o comércio exterior do país, pois $94 \%$ dele é realizado por vias marítimas. Assim, tais deficiências aumentam os custos para o setor produtivo, pois o tempo despendido nessa etapa do ciclo logístico das exportações é maior. (Martone et al., 2004).

Além disso, sobre os serviços prestados pelos setores de infra-estrutura incidem elevados tributos, o que torna mais onerosa a utilização deles pelo setor produtivo. As cargas tributárias dos setores de transporte, energia elétrica e telecomunicação, no Brasil, são de 50,85\% (Instituto Brasileiro de Planejamento Tributário - IBPT, 2002), 40,52\% (Teles et al., 2004) e 30,38\% (Melo and Melchior, 2003) da receita bruta, respectivamente.

Os impostos sobre energia elétrica, em países desenvolvidos, são inferiores a um terço dos cobrados no Brasil, como, por exemplo, na Alemanha, nos Estados Unidos e na França, cuja carga tributária é de $13,8 \%, 8,2 \%$ e 5,2\%, respectivamente (Multidoc, 2005). Os impostos cobrados sobre telefonia também são elevados, se comparados aos de outros países, como Itália (20\%), Espanha (16\%) e Índia (8\%) (Guerreiro, 2005).

Assim, os elevados custos com serviços de infra-estrutura, em razão do mau estado de conservação, da falta de investimentos no setor e dos altos tributos que incidem sobre eles, deixam o setor produtivo menos competitivo e causam redução no bem-estar econômico. 
Posto isso, torna-se relevante conhecer os impactos de políticas que proporcionem redução nos custos desses serviços para o setor produtivo e para o consumidor final na economia brasileira. Mediante os resultados de uma pesquisa que investigue esses pontos, é possível fornecer subsídios à tomada de decisão de investimentos entre os setores de infra-estrutura, como transportes, energia elétrica e telecomunicações. É também importante conhecer os benefícios oriundos de uma desoneração fiscal sobre os serviços prestados por esses setores, os quais possam orientar o governo.

O objetivo deste artigo é determinar os impactos da redução nos custos dos serviços de infraestrutura, mediante aumento na oferta e desoneração tributária, no setor produtivo da economia brasileira e os efeitos no bem-estar das famílias.

É importante considerar que questões relacionadas com o tema foram investigadas por vários autores. Aschauer (1989) deu início a essa linha de pesquisa, ao analisar os efeitos dos gastos públicos em infra-estrutura sobre o crescimento econômico dos Estados Unidos, de 1949 a 1985. Ferreira and Malliagros (1998) analisaram o caso brasileiro no período de 1950 a 1995, ao dividirem a infra-estrutura em transporte, comunicação e energia. Investigaram os efeitos dos investimentos públicos e do estoque de capital nesses setores sobre o crescimento da renda e da produtividade total dos fatores.

Embora apresentem contribuição relevante na análise e investigação empírica dos efeitos da infraestrutura, os trabalhos citados necessitam de estudos complementares que contornem suas limitações, para servirem de base para elaboração de políticas. Essas limitações se devem, principalmente, ao fato de tratarem a economia de forma muito agregada, ou por realizarem análise de equilíbrio parcial. Ferreira and Malliagros (1998), embora tenham utilizado a econometria de séries temporais, reconheceram que as suas conclusões seriam insuficientes para recomendar investimentos em setores específicos, sugerindo um trabalho que utilize a análise de equilíbrio geral para maior embasamento de tais recomendações de políticas quanto aos setores de infra-estrutura.

A contribuição desta pesquisa está, portanto, na análise do problema exposto, utilizando-se do modelo de equilíbrio geral. Dada a relevância do setor de infra-estrutura para o crescimento econômico, a redução nos custos dos seus serviços provoca impactos significativos em grande número de mercados de bens e de fatores que, direta ou indiretamente, utilizam-se desses serviços. Assim, a escolha do método de análise de equilíbrio geral deve-se, principalmente, a esse fato, pois a redução no custo de utilização dos serviços de infra-estrutura para o setor produtivo implica detalhado processo de realimentação de impulsos e respostas, dadas as interdependências do sistema de preços, que afeta também a utilidade do consumidor final.

Além dessa introdução, este artigo apresenta, nas seções seguintes, uma revisão da literatura relevante à análise do problema exposto e a descrição da metodologia utilizada. São expostos ainda os resultados e as conclusões obtidos da pesquisa.

\section{INFRA-ESTRUTURA NAS TEORIAS DO CRESCIMENTO}

As investigações científicas sobre os impactos econômicos da infra-estrutura, geralmente, são abordadas sob a ótica do crescimento econômico e seus fatores condicionantes.

Na década de 1950, foi dada grande contribuição à teoria do crescimento econômico mediante metodologia e linguagem neoclássica. Trata-se dos modelos desenvolvidos por Solow e Swan, que ficaram conhecidos como modelos de crescimento exógeno. No modelo de Solow, as taxas de crescimento do consumo e da renda, no longo prazo, dependem da taxa de mudança tecnológica, que é determinada exogenamente (Pereira and Araújo, 1997). A acumulação de capital desempenha papel relevante nesse modelo. Haverá crescimento na economia enquanto a variação de estoque de capital per capita for positiva, ou seja, enquanto o nível de investimento for maior que a depreciação do capital. Quando forem iguais, a economia alcançará o steady state ou estado estacionário. Um aumento na taxa de poupança e, conseqüentemente, no nível de investimento levaria ao crescimento, até a obtenção de um novo estado estacionário. No entanto, somente o progresso tecnológico, que provocaria sucessivos 
deslocamentos da função de produção para cima, permitiria o crescimento do produto por trabalhador, ao longo do tempo (Mendes and Vale, 2001).

O modelo de crescimento exógeno, embora identifique o progresso tecnológico como impulsionador do crescimento, não explica o que o causa. Para dar essa resposta, na década de 1980, outra teoria foi desenvolvida a do crescimento endógeno. Segundo ela, o progresso tecnológico é determinado pelo próprio processo de crescimento - por isso, usa-se o termo endógeno (Carvalho, 2004). O marco inicial de trabalhos nesta linha foi o modelo de Romer, publicado em 1986, no qual a medida de capital passou a ser interpretada de forma ampla, contendo o capital físico, o capital humano ou o estoque de conhecimento e qualquer outro fator de produção acumulável. O avanço tecnológico origina-se de atividades deliberadas dos agentes, motivados pelo interesse de obtenção de maiores lucros ou utilidade. A taxa média de descobertas é endógena, pois, quanto mais pessoas estiverem trabalhando em pesquisa, maiores serão as chances de ocorrerem novas descobertas. As descobertas são diferentes de outros insumos por serem não-excludentes, ou seja, muitas pessoas podem usá-las ao mesmo tempo. O modelo pressupõe retornos crescentes para o capital, de forma que o retorno ao capital será sempre maior que a sua depreciação, sendo possível haver crescimento permanente de consumo e capital (Pereira and Araújo, 1997).

De acordo com (Bernard and Garcia, 1995), o investimento em infra-estrutura física tem sido apontado como de grande relevância para o crescimento econômico, enquanto acumulação de capital físico. Entretanto, as teorias de crescimento expostas possuem diferentes visões em relação aos efeitos desse capital de infra-estrutura sobre o crescimento econômico. Segundo a teoria do crescimento exógeno, os gastos com esse capital afetam a taxa de crescimento apenas na transição para o estado estacionário. No entanto, de acordo com a teoria do crescimento endógeno, esses efeitos temporários tornam-se permanentes.

Hirschman (1983) destacou o papel da infra-estrutura na sua teoria do crescimento desequilibrado, segundo a qual, o crescimento se dá a partir de um desequilíbrio inicial em um setor, o qual acaba por desencadear uma série de investimentos adicionais na economia. Esses desencadeamentos serão tanto mais significativos quanto maior for a indução desse setor, dada pelas suas interligações com os demais setores. Assim, o desenvolvimento é resultante da indução ao investimento por meio de desequilíbrios. A indução a investir é elevada pela expectativa de obtenção de lucro e economias externas, que seriam oriundas da infra-estrutura econômica, como rodovias, usinas hidrelétricas etc., que reduzem os custos de produção e elevam a taxa de retorno para os investimentos. Cada investimento induz a uma série de investimentos subseqüentes e haverá convergência na seqüência de investimentos, à medida que as economias externas diminuem. Hirschman chamou a atenção para o fato de que excessivos desequilíbrios em favor de investimentos em infra-estrutura podem ser prejudiciais às economias em desenvolvimento. A dotação insuficiente de infra-estrutura, que inibe o crescimento, pode levar o setor público a realizar elevados investimentos, mas, à medida que o capital fixo ficar ocioso, acarretará grandes despesas na sua manutenção (Souza, 1995).

A infra-estrutura é considerada necessária para obtenção de competitividade sistêmica, principalmente de telecomunicação e rodovias. Para Suzigan and Fernandes (2003), a competitividade deve estar fundamentada no binômio crescimento com eqüidade distributiva. Esses autores conceituaram competitividade sistêmica como um conjunto de medidas que capacitam um país a expor-se ao mercado externo e manter ou elevar a qualidade de vida de sua população, fortalecendo não apenas as empresas, mas a economia como um todo. Essas medidas ou políticas, de caráter sistêmico, deveriam fomentar a inovação tecnológica e o sistema educativo, apoiar a pequena empresa e melhorar a infra-estrutura etc. A competitividade sistêmica é diferente da competitividade espúria, que se dá pelos baixos salários, por subsídios e por câmbio desvalorizado.

Dumont and Mesplé-Somps (2000) desenvolveram um modelo que mostra que gastos governamentais em infra-estrutura não têm apenas efeito de absorção, como os demais gastos, mas efeito de expansão, representado pelo deslocamento da curva de possibilidade de produção, dada pelos efeitos externos que o acréscimo na disponibilidade de infra-estrutura proporciona, elevando a produtividade. 
Esses autores analisaram os efeitos da expansão na capacidade de produção de setores tradable e non tradable. $O$ aumento nos gastos governamentais e a conseqüente expansão da renda dos agentes privados causam apreciação da taxa de câmbio real. Contudo, esse impacto é relativamente fraco e há elevação nas exportações, como conseqüência das mudanças de produtividade nos setores econômicos.

As análises e pressuposições acerca dos impactos da infra-estrutura no crescimento seguem, aproximadamente, a mesma linha. A infra-estrutura cria condições favoráveis à produção; eleva a competitividade e produtividade dos investimentos, reduzindo custos de produção; e influencia, de forma direta e indireta, o emprego, a renda e o bem-estar.

\section{TRIBUTAÇÃO E EFICIÊNCIA}

Um sistema tributário ideal deve atender aos princípios de eqüidade, progressividade, simplicidade e neutralidade. A eqüidade pode estar baseada nos princípios do benefício ou da capacidade de pagamento. De acordo com o princípio do benefício, cada indivíduo deverá contribuir de forma proporcional aos benefícios gerados pelo consumo de bens públicos. O princípio da capacidade de pagamento define que contribuintes com a mesma capacidade de pagamento devem pagar a mesma alíquota de imposto; assim, quanto maior a capacidade de pagamento, maior a contribuição do indivíduo. Baseado neste último argumento está o princípio da progressividade, que significa uma razão tributo/renda crescente. O princípio da simplicidade está relacionado com a facilidade da operacionalização da cobrança do tributo. A neutralidade está relacionada com o conceito de eficiência econômica. Um imposto neutro é aquele que não interfere nas decisões de alocação de recursos. Essas decisões são consideradas eficientes quando baseadas nos preços relativos determinados pelo mercado. Se a tributação alterar os preços relativos, conduzirá à distorção na alocação dos recursos e, assim, à redução no nível geral de bem-estar social (Smith, 1981).

Os impostos podem ser diretos ou indiretos. Os diretos são aqueles cuja incidência se dá sobre os rendimentos dos indivíduos, sejam estoques de riqueza acumulada, seja fluxo de renda. Os impostos indiretos, por sua vez, incidem sobre o fluxo dos produtos e serviços no mercado. Nessa última categoria de impostos, os contribuintes podem transferir total ou parcialmente o seu ônus para terceiros, dependendo a parcela dessas transferências das elasticidades preços da demanda e da oferta.

A tentativa de evitar o imposto pela transferência torna-se complexa, dadas as numerosas interdependências do sistema de preços. O impacto inicial da incidência de um imposto se dá para a pessoa física ou jurídica, responsável legal pelo seu pagamento. A transferência ocorre quando esses primeiros impactados tentam repassar o ônus do imposto para outras pessoas. Essa transferência pode ser para frente, quando o tributo é repassado, total ou parcialmente, ao consumidor, por meio de preços mais elevados do produto, ou para trás, quando se dá no sentido do mercado de fatores, por meio de menores pagamentos pela utilização do capital e do trabalho (Filelline, 1989).

Assim, em virtude da complexidade de impactos e da abrangência dos agentes que, direta ou indiretamente, são afetados com a introdução de um imposto, o equilíbrio geral torna-se adequado à análise desse tipo de problema econômico, por considerar as interligações entre os mercados e as ações dos agentes. No caso dos impostos que incidem sobre os serviços de infra-estrutura, as distorções se dão, principalmente, pelo aumento no custo relativo da utilização desses fatores pelo setor produtivo, o que implica maior dificuldade do crescimento setorial e global, em razão da relevância dos setores de infra-estrutura e de seus serviços para os demais setores da economia.

\section{MODELO ANALÍTICO}

Os Modelos Aplicados de Equilíbrio Geral (MAEGs) determinam, endogenamente, os preços relativos e as quantidades produzidas, por meio de programas microeconômicos de otimização, resolvendo, nu- 
mericamente, o problema de equilíbrio geral. Os MAEGs fornecem resultados abrangentes e detalhados dos efeitos de mudanças políticas sobre as economias analisadas (Fochezatto, 2002).

Os agentes analisados no MAEG estruturado, nesta pesquisa, são as Famílias, os Setores Produtivos, o Governo e o Resto do Mundo.

Os comportamentos, as motivações e as restrições dos agentes devem ser bem caracterizados pelas formas funcionais das equações, utilizadas para representar o sistema de equilíbrio. No MAEG utiliza-se do pressuposto de comportamento otimizante dos agentes, considerando a existência de restrições. No modelo especificado neste artigo, os setores produtivos combinam fatores obedecendo ao critério de otimização do setor produtivo, ou seja, maximização do lucro ou minimização de custos, considerando a existência de restrições de tecnologia e de disponibilidade de recursos na otimização.

As famílias, também regidas por comportamento otimizante, visam maximizar utilidade, dadas suas restrições orçamentárias. Essa maximização é restrita à renda disponível do consumidor, que é constituída pelo valor das vendas dos serviços dos fatores mais as transferências governamentais e externas, deduzidos os impostos.

O Governo desenvolve dois tipos de atividades: a oferta de bens e serviços públicos sem estabelecimento e com estabelecimento de preços. Sua receita é composta pelos impostos e pelas tarifas sobre importações. Demanda bens e serviços, faz transferência às famílias e poupa (Ponciano, 2000). Os impostos cobrados na prestação de serviços de infra-estrutura constituem parte da receita do Governo.

O Resto do Mundo representa o setor externo da economia. Por meio dele são representadas as exportações do setor produtivo e as importações do setor produtivo e das famílias e, ainda, o recebimento e as transferência de renda desse agente e dos agentes domésticos, e a formação de poupança externa.

No equilíbrio de mercado, os preços e a produção devem ser tais, que a oferta de um produto seja maior ou igual ao excesso de demanda, e, no equilíbrio da renda, o valor da renda de cada agente deve ser igual ao valor da sua dotação de fatores.

Pressupõe-se que o investimento seja igual à poupança e que esta seja formada pelas poupanças do setor privado, do governo e da poupança externa (Lírio, 2001).

Apesar de os MAEGs serem pautados nos comportamentos dos agentes, o que revela seu embasamento microeconômico, é preciso conciliá-los com fundamentos macroeconômicos, o que consiste no fechamento do modelo. Em termos matemáticos, o problema do fechamento consiste em eliminar uma equação do sistema de equações dos MAEGs que são sobredeterminados. $O$ fechamento utilizado neste trabalho será o neoclássico, que pressupõe a igualdade entre poupança e investimento agregado. É possível admitir, no fechamento neoclássico, flexibilizações como superávit ou déficit no balanço de pagamentos ou orçamento do governo e plena utilização, ou não, dos fatores disponíveis.

Todos os preços são tratados de forma relativa, e os preços, em sua forma absoluta, não têm significado em um MAEG. Escolhe-se, nesse modelo, o preço de um mercado para ser usado como referência para os demais preços. A normalização consiste na escolha desse preço ou conjunto de preços, isto é, na escolha de um numerário (Braga, 1999), cujo valor é fixado exogenamente, geralmente igual à unidade. Lírio (2001) salientou que a escolha do numerário deve atender às expectativas do pesquisador, recaindo sobre uma variável representativa para o modelo. Nesta pesquisa será utilizado o índice de preço ao consumidor, ponderado pela participação dos bens no consumo das famílias. A escolha desse numerário deve-se à influência dos preços ao consumidor no bem-estar, pois, na determinação dessa variável, o consumo das famílias será utilizado como proxy da utilidade, como será especificado na seção seguinte.

Nos MAEGs, os parâmetros relevantes para o funcionamento do modelo são geralmente calibrados, e não estimados como nos modelos econométricos, isto é, os parâmetros são calculados a partir de uma única observação das variáveis exógenas em determinado ano base, que servirá de referência para as simulações. Assim, calibrar o modelo significa calcular os valores para seus parâmetros, de forma a garantir que os dados do ano base sejam uma solução de equilíbrio. Quando esses parâmetros não puderem ser calculados, deverão ser obtidos de outras fontes da literatura, ou até mesmo arbitrariamente (Ferreira Filho, 1998). 


\subsection{Modelo matemático}

O modelo é constituído por um conjunto de equações não-lineraes, do qual se obtém a alocação de recursos por meio do sistema de preços, expressos de forma relativa. As equações estão no formato CES, podendo assumir formas especiais desta, de acordo com o valor da elasticidade de substituição. 0 modelo, exposto a seguir, é baseado em Oliveira (2006).

O modelo apresenta quatro conjuntos e duas classes de funções. Os conjuntos de funções são referentes às mercadorias, consumidores, produtores e restrições auxiliares, e as classes de funções, às de utilidade e de produção.

Na notação utilizada, as variáveis endógenas estão em letras maiúsculas, enquanto as exógenas estão em letra minúscula e os parâmetros, em letras gregas. Os índices sub e sobrescritos indicam os setores quando forem $i$ e $j ; f$, fatores primários; $h$, famílias; $g$, governo; e $x$, setor externo.

As equações de (01) a (04) representam a estrutura das atividades produtivas.

$$
\begin{gathered}
C I_{i}=\sum_{j} \alpha_{i j} P D_{j} \\
V A_{i}=\epsilon_{i}\left[\delta_{i} L^{\frac{\sigma_{i}^{s}-1}{\sigma_{i}^{s}}}+\left(1-\delta_{i}\right) K^{\frac{\sigma_{i}^{s}-1}{\sigma_{i}^{s}}}\right]^{\frac{\sigma^{s} i}{\sigma_{i}^{s}-1}} \\
D F_{i L}=\epsilon_{i}^{-1}\left[\left(1-\delta_{i}\right)\left(\frac{\delta_{i} P_{K}^{*}}{\left(1-\delta_{i}\right) P_{L}^{*}}\right)^{1-\sigma_{i}^{s}}+\delta_{i}\right]^{\frac{\sigma_{i}^{s}}{1-\sigma_{i}^{s}}} \\
D F_{i K}=\epsilon_{i}^{-1}\left[\delta_{i}\left(\frac{\delta_{i} P_{K}^{*}}{\left(1-\delta_{i}\right) P_{K}^{*}}\right)^{1-\sigma_{i}^{s}}+\left(1-\delta_{i}\right)\right]^{\frac{\sigma_{i}^{s}}{1-\sigma_{i}^{s}}}
\end{gathered}
$$

A equação (1) representa o consumo intermediário $\left(C I_{i}\right)$, modelado no formato $\mathrm{CES}$, das mercadorias compostas $\left(P D_{j}\right)$, que são agregações CES de produtos importados ou produzidos internamente, em que $\alpha_{i j}$ é o parâmetro de produtividade.

O valor adicionado $\left(V A_{i}\right)$ de cada atividade considerada no modelo é composto dos fatores básicos capital $(K)$ e trabalho $(L)$, que são homogêneos e móveis entre os setores componentes na economia. $O$ valor adicionado é modelado por uma função CES, expresso pela equação (2), em que $\epsilon_{i}$ e $\delta_{i}$ são parâmetros de produção e $\sigma_{i}^{s}$, elasticidade de substituição.

As demandas dos fatores por unidade de valor adicionado são representadas pelas equações (3) e (4). Cada setor produz um único produto e apresenta retornos constantes à escala. Como já mencionado, o comportamento do produtor é caracterizado pela minimização dos custos, e acrescenta-se a restrição de que o valor adicionado some 1 . Nessas equações, $D F_{i L}$ e $D F_{i K}$ representam as demandas dos fatores trabalho e capital, respectivamente. Nesse bloco, tem-se a estrutura produtiva do modelo representada por $4 \mathrm{n}$ equações, em que $\mathrm{n}$ é número de setores.

As quantidades e preços do modelo são representados pelas equações (5) a (13).

$$
\begin{gathered}
P D_{i}=\beta_{i}\left[\gamma_{i} X_{i}^{\rho_{i}^{t}}+\left(1-\gamma_{i}\right) V D_{i}^{\rho_{i}^{t}}\right]^{\frac{1}{\rho_{i}^{t}}} \\
X_{i}=V D_{i}\left[\frac{P_{i}^{X}\left(1-\gamma_{i}\right)}{P_{i}^{d} \gamma_{i}}\right]^{\frac{1}{\left(\rho_{i}^{t}-1\right)}} \\
O B S_{i}=\epsilon_{i}\left[\delta_{i} M_{i}^{-\rho_{i}^{s}}+\left(1-\delta_{i}\right) V D_{i}^{-\rho_{i}^{s}}\right]^{\frac{-1}{\rho_{i}^{s}}}
\end{gathered}
$$




$$
\begin{gathered}
X_{i}=X_{i}^{o}\left(P^{X}\right)^{v}\left(\frac{\sum_{i=1}^{n}\left(P^{X}\right)^{1+v} X_{i}^{o}}{\sum_{i=1}^{n}\left(P^{M}\right)^{1+\mu} M_{i}^{o}}\right)^{\frac{v}{\mu-v}} \\
M_{i}=V D_{i}\left[\frac{P_{i}^{d}\left(1-\delta_{i}\right)}{P_{i}^{M} \delta_{i}}\right]^{\frac{1}{1+\rho_{i}^{S}}} \\
P_{i}^{M}=p w_{i}^{m}\left(1+t_{i}^{m}\right) t x \\
P_{i}^{X}=p w_{i}^{x}\left(1+t_{i}^{x}\right) t x \\
P_{i}^{q} O B S_{i}=P_{i}^{d} V D_{i}+P_{i}^{m} M_{i} \\
P_{i}^{P D} P D_{i}=P_{i}^{d} V D_{i}+P_{i}^{x} X_{i}
\end{gathered}
$$

A produção doméstica $\left(P D_{i}\right)$ é expressa pela equação (05) e mostra que esta pode ser uma combinação entre venda domésticas $\left(V D_{i}\right)$ e as destinadas as exportações $\left(X_{i}\right)$, sendo modelada por uma função CET. Nessa equação, $\beta_{i}$ é o parâmetro tecnológico; $\gamma_{i}$, parâmetro de distribuição da função; e $\rho_{i}^{t}$, parâmetro de transformação.

A equação (6) mostra a oferta de exportação. Como se pode observar, a decisão dos produtores nacionais de exportar os produtos é função dos preços relativos nos mercados externo e doméstico $P_{i}^{X} / P_{i}^{d}$, do parâmetro de distribuição funcional $\left(\gamma_{i}\right)$ e da elasticidade de transformação $\left(1 /\left(\rho_{i}^{t}-1\right)\right)$, que é igual a $\sigma_{i}^{t}$.

A oferta de bens e serviços $\left(O B S_{i}\right)$ é um composto entre os bens importados $\left(M_{i}\right)$ e domésticos $\left(X_{i}\right)$, agregados em uma função CES, que exprime a substitutibilidade imperfeita entre esses bens. Essa oferta é representada pela equação (7), em que $\delta_{i}$ é o parâmetro de distribuição e $\rho_{i}^{s}$, o de substituição.

A demanda de exportações é representada pela equação (8), expressa em função dos preços nacionais.

A demanda de importação é exposta, na equação (9), como uma função dos preços relativos e dos parâmetros da função CES, principalmente da elasticidade de substituição $\left(1 /\left(1+\rho_{i}^{s}\right)\right)$.

Os preços externos, considerados como exógenos, são expressos nas equações (10) e (11). Essas equações mostram os preços domésticos de importações $\left(P_{i}^{M}\right)$ e exportações $\left(P_{i}^{X}\right)$, que são função dos preços internacionais, $p w_{i}^{m}$ e $p w_{i}^{x}$, respectivamente, ajustados pelas tarifas de importação $\left(t_{i}^{m}\right)$, impostos de exportação $\left(t_{i}^{x}\right)$ e taxa de câmbio nominal $(t x)$.

Os valores das ofertas de bens e serviços disponíveis no mercado $\left(O B S_{i}\right)$ e da produção setorial $\left(P D_{i}\right)$ são representados pelas equações (12) e (13), respectivamente. A primeira é composta pelo valor das vendas domésticas $\left(V D_{i}\right)$ e compras externas $\left(M_{i}\right)$, e a segunda é uma agregação de $V D_{i}$ e exportações $\left(X_{i}\right)$. Nessas equações, $P_{i}^{q}$ e $P_{i}^{P D}$ são, respectivamente, os preços domésticos dos bens e serviços disponíveis e o preço da produção doméstica. Considerando a existência de n setores, têm-se, nesse bloco, 9n equações.

O bloco seguinte de equações representa as rendas das famílias e do governo e a poupança, composto pelas equações (14) a (25).

$$
\begin{gathered}
Y_{f}=\sum_{i} W_{f} \cdot D F_{i f} \\
Y_{c}=\sum_{f} Y_{f}+\sum T R_{\mathrm{g} / \mathrm{fam} \text { ílias }}
\end{gathered}
$$




$$
\begin{gathered}
C P=Y_{c}\left(1-t_{f}\right) \cdot \tau_{f} \\
S_{p}=Y_{c} \cdot\left(1-t_{f}\right) \cdot v_{f} \\
T I M=\sum_{i} p w_{i}^{m} \cdot M_{i} \cdot t_{i}^{m} \cdot t x \\
T I=\sum_{i} P_{i}^{P D} \cdot P D_{i} \cdot t_{i}^{P D} \\
T D=Y_{f} t_{f} \\
T E X=\sum_{i} p w_{i}^{x} \cdot X_{i} \cdot t_{i}^{x} \cdot t x \\
R G=T I M+T I+T D+T E X \\
S_{g}=R G-\left(\sum_{i} P_{i}^{O B S_{i}} \cdot C G_{i}\right) \\
C G_{i}=G D T O T+T R_{g} \\
S=S_{p}+S_{g}+\left(S_{x} \cdot t x\right)
\end{gathered}
$$

A renda interna dos fatores, como função do somatório do produto do preço médio dos fatores $\left(\sum_{i} W_{f}\right)$ e da demanda de fatores $\left(D F_{i f}\right)$, é definida na equação (14). A equação (15) mostra que essa renda é destinada às famílias e que, somada às transferências realizadas pelo governo ( $\left.T R_{\mathrm{g} / \text { famílias }}\right)$, obtém-se a renda total das famílias.

As famílias optam por alocar a sua renda entre consumo ou poupança. O consumo das famílias é definido com base na renda disponível, que é dada pela diferença entre a renda e os impostos diretos $\left(Y_{c} .\left(1-t_{f}\right)\right)$, e na propensão marginal a consumir $\left(\tau_{f}\right)$, e a poupança é definida pela renda disponível e pela propensão marginal a poupar $\left(v_{f}\right)$, como mostrado nas equações (16) e (17), respectivamente.

A receita do governo é formada pelos impostos cobrados. As equações (18) a (21) representam as receitas auferidas das tarifas de importação (TIM), dos impostos indiretos (TI), dos impostos diretos (TD) e dos impostos incidentes sobre o valor das exportações (TEX). A equação (22) representa a receita total do governo.

A poupança do governo é definida pela diferença entre a sua receita total e seus gastos com bens e serviços, como mostrado na equação (23), sendo esse último dado pela soma do produto entre o preço dos bens e serviços disponíveis $\left(P_{i}^{O B S_{i}}\right)$ e o consumo do governo $\left(C G_{i}\right)$. A equação (24) define $C G_{i}$ pela soma do dispêndio real do governo com bens e serviços (GDTOT) e as transferências realizadas para as famílias (TRg).

A poupança total da economia é formada pelas poupanças privadas $\left(S_{p}\right)$, do governo $\left(S_{g}\right)$ e externa $\left(S_{x}\right)$, como mostrado na equação (25). Nessa equação, $t x$ é a taxa de câmbio.

No presente modelo são considerados dois consumidores, cujas rendas, consumos e poupanças estão representados pelas 12 equações desse bloco.

o bloco de equações seguinte apresenta as condições de equilíbrio e o fechamento do modelo.

$$
O B S_{i}=C I_{i}+C P_{i}+C G_{i}+\Delta E S T_{i}
$$




$$
\begin{gathered}
\sum_{i} D F_{i f}=f s_{f} \\
p w_{i}^{x} X_{i}+S_{x}=p w_{i}^{m} \cdot M_{i}+y_{x} \\
S=I
\end{gathered}
$$

No equilíbrio no mercado de bens, obtido dos preços de equilíbrio, demanda e oferta de bens são iguais para cada setor produtivo. Essa condição é expressa na equação (26), em que $C P_{i}$ é o consumo do setor privado e $\Delta E S T_{i}$, variação nos estoques.

O equilíbrio no mercado de fatores é obtido de forma idêntica ao de bens, sendo expresso pela equação (27), em que $f s_{f}$ é a dotação de fatores, considerada fixa, mas móvel entre as atividades.

o equilíbrio no mercado externo é garantido pela igualdade entre poupança externa e déficit do balanço de pagamentos em conta corrente, como mostrado na equação (28), em que $y_{x}$ é a renda líquida enviada ao exterior.

A equação (29) expressa a identidade macroeconômica entre poupança e investimento, representando a equação de fechamento do modelo (neoclássico), conhecido como demanda-dirigido, que pressupõe que a economia trabalhe com capacidade ociosa, e, assim, flutuações na demanda final são prontamente atendidas pelo setor produtivo (Sadoulet and De Janvry, 1995). Nesse bloco, as equações que representam as condições de equilíbrio e fechamento totalizam $n+3$.

A equação seguinte representa o numerário escolhido para o modelo, que foi o índice de preço ao consumidor, definido pelo somatório dos bens ponderados pela sua participação no consumo.

$$
N U M=\sum_{i} z_{i} P_{i}^{P D_{i}}
$$

em que $z_{i}$ é o parâmetro que mede a participação do produto de cada setor no consumo total das famílias.

Por fim, define-se, algebricamente, a medida de bem-estar utilizada, a variação equivalente (VE), que quantifica as mudanças necessárias na renda inicial, aos preços de equilíbrio inicial, para que os consumidores possam manter os mesmos níveis de utilidade quando se deparam com os níveis de preços do equilíbrio final (Varian, 1993). Quando VE apresenta valores positivos, indica que há melhorias no bem-estar social, o que reflete o acréscimo no nível de satisfação dos consumidores; caso contrário, apresenta valores negativos. Essa medida é calcula pela seguinte expressão:

$$
V E=\frac{\left(U^{F}-U^{I}\right)}{U^{I}} I^{I}
$$

em que $U^{I}$ e $U^{F}$ são os níveis de utilidade nos equilíbrios inicial e final, ou seja, os níveis de utilidade do benchmark e contra-factual, respectivamente, e $I^{I}$, renda dos consumidores no equilíbrio inicial. Como proxy da utilizada será utilizada a variável consumo das famílias ou consumo privado, definida anteiormente.

Considerando os blocos de equações apresentados, verifica-se que o modelo possui $4 n+9 n+12+$ $n+3+2$ equações, que totalizam $14 n+17$ equações. Como será apresentado na seção seguinte, neste trabalho $\mathrm{n}=9$, tendo, portanto, o modelo utilizado 143 equações.

\subsection{Cenários}

A redução nos custos de utilização dos serviços de transporte, energia elétrica e telecomunicações para o setor produtivo pode vir do aumento da oferta ou qualidade desses serviços ou da redução na carga tributária incidente sobre sua utilização. A maioria dos trabalhos que investigam a importância 
da infra-estrutura para o crescimento objetiva encontrar a relação ou montante de investimento nos setores de infra-estrutura e a taxa de crescimento resultante. Neste artigo, a utilização desse tipo de choque de variação em investimentos não será utilizada, pois, segundo Sadoulet and De Janvry (1995), em MAEGs na forma estática, variações no nível de investimento subseqüente a mudanças na poupança apresentam pequenas variações, o que afeta apenas o nível de demanda e não capta o fato de que, em perspectivas de longo prazo, o investimento é o principal determinante do crescimento. ${ }^{1}$

Assim, serão formulados dois tipos de cenários, aumento na oferta dos serviços de infra-estrutura e redução nos tributos sobre esses serviços, descritos a seguir.

\subsubsection{Cenários de aumento na oferta de serviços de infra-estrutura}

Transporte De acordo com dados da Confederação Nacional do Transportes Confederação Nacional Dos Transportes (CNT) (2005), a matriz de transportes de cargas no Brasil tem a seguinte composição entre os modais existentes: rodoviário, 61,1\%; ferroviário, 20,7\%; aquaviário, 13,6\%; dutoviário, 4,2\%; e aéreo $0,4 \% .^{2}$ Os choques de aumento na oferta de cada modal serão ponderados pela sua participação no transporte de cargas, sendo o crescimento da oferta total do setor dada pela equação seguinte.

$$
\text { crescimento }=\sum_{i=1}^{n} \text { crescimento }_{i} * \text { participação }_{i}
$$

em que $n$ é o número de modais existentes.

Segundo pesquisa da CNT realizada em 2005, considerando-se os itens pavimentação, sinalização e geometria das vias, apenas $28 \%$ das rodovias brasileiras são consideradas ótimas e boas (Tabela 1). A pesquisa foi realizada em uma amostra de $81.944 \mathrm{~km}$ de extensão de rodovias, entre as de administração estatal e privada. Quando se utilizam os resultados obtidos por essa pesquisa para classificar o total de rodovias brasileiras $(1.610 .076 \mathrm{~km})$ quanto a qualidade, encontra-se uma extensão de $450.821,28 \mathrm{~km}$ pertencente à classificação ótima e boa. De acordo com o Ministério dos Transportes (2006), a previsão é de recuperação de $65.955 \mathrm{~km}$ de rodovias federais, incluindo as obras já em andamento. Somado ao percentual de rodovias consideradas boas e ótimas, o percentual, com essa classificação, passará para 32,10 , o que representa um aumento de $14,63 \%$ na oferta de rodovias ótimas e boas. Essa será a proxy utilizada na construção do cenário de crescimento de oferta de serviços de transporte rodoviário. Ponderando esse aumento pela participação do modal na matriz de transporte de carga, obtém-se um crescimento de $8,94 \%$ na oferta do serviço de transporte rodoviário, sendo esse o percentual a ser simulado no modelo de equilíbrio geral utilizado.

Table 1: Qualidade das rodovias brasileiras - 2005

\begin{tabular}{|l|c|}
\hline Estado geral & $\%$ \\
\hline Ótimo & 11 \\
Bom & 17 \\
Regular & 31,8 \\
Ruim & 22 \\
Péssimo & 18,2 \\
\hline
\end{tabular}

Fonte: Confederação Nacional Dos Transportes (CNT) (2005).

\footnotetext{
${ }^{1}$ Para uma análise dinâmica sobre os investimentos em infra-estrutura ver Ferreira and Nascimento (2006).

${ }^{2}$ Esses dados são referentes ao ano de 2005. Entretanto, como pode ser observado em Schroeder and Castro (1996), não existem grandes diferenças na Matriz de Transportes de Cargas desse ano e as dos primeiros anos da década de 1990. Assim, será utilizada a matriz de 2005 para elaboração dos cenários.
} 
De acordo com dados da Agência Nacional de Transportes Terrestres (Agência Nacional de Transportes Terrestres, 2006), em 2004, a produção de transporte ferroviário foi de 205.711 milhões de TKU (Toneladas Quilômetro Útil). ${ }^{3}$ Essa é uma medida de desempenho do setor e será utilizado como proxy para o cálculo do aumento da oferta dos serviços desse setor. Nos anos de 1996 a 2004, houve aumento de $60 \%$ na produção de transportes ferroviários. Há uma meta, divulgada pela ANTT, de ampliação desse aumento para $126,8 \%$ até 2007 . Ponderando-se esse aumento na produção de transporte ferroviário pela participação do setor no transporte de cargas, obtém-se um acréscimo de $26,25 \%$ no aumento de oferta do setor, valor que será utilizado nas simulações.

A evolução da movimentação de cargas nos portos brasileiros mostra um crescimento de $60,65 \%$ no total de cargas em toneladas, nos anos de 1996 a 2004, segundo a Agência Nacional de Transportes Aquaviários (Agência Nacional de Transportes Aquaviários, 2005). Pela indisponibilidade de metas futuras divulgadas pelos órgãos responsáveis, esse valor será utilizado, como proxy, na construção do cenário de aumento de oferta. O crescimento ponderado pela participação do modal no transporte de cargas a ser simulado é de $8,25 \%$.

A soma das médias ponderadas, que é igual a 43,44\%, representa o acréscimo de oferta total do setor de transportes. Para simulação será considerado que a meta de expansão é para o período que vai de 1996 ao ano de 2004, portanto 9 anos e, assim a média é de um crescimento de 4,83\% a.a., sendo esse o valor usado no cenário.

Energia elétrica A capacidade atual de geração de energia elétrica no país é de 92.350 MW, segundo dados do Governo Federal. Há uma meta de ampliação dessa capacidade para 96.359 MW, com a construção de novas usinas. O alcance dessa meta representará um acréscimo de $58,5 \%$ na capacidade de geração no período de 1996 a 2005 (de Minas e Energia (MME), 2005). A média desses 11 anos é de crescimento de $5,32 \%$ a.a. Esse acréscimo será utilizado na construção do cenário como proxy do aumento da oferta de energia elétrica.

Telecomunicações A Agência Nacional de Telecomunicações (Agência Nacional de Telecomunicações, 2005) possui uma Perspectiva para Ampliação e Modernização do Setor de Telecomunicações (PASTE) que define as metas para o setor. Tal documento definiu o aumento na oferta médio de $684,46 \%$ entre os setores de telefonia fixa e móvel, redes e circuitos, radiochamadas e televisão por assinatura. De acordo com o Banco da Amazônia (Banco Da Amazônica (BASA), 2004), a participação do setor de telecomunicações em Comunicações é de $87,41 \%$. Ponderando o aumento da oferta pela participação do setor, obtém-se um aumento de 598,29\%. É preciso informar que a base de dados de 1996 não suporta a simulação desse crescimento para o setor. 0 máximo que a base de dados suportou foi um choque de aumento de oferta de $247 \%$. Entretanto, ao usar esse valor para simulações obtiveram-se resultados não condizentes com a teoria ou com a realidade, devido às profundas transformações tecnológicas que ocorreram no setor, para que pudesse ser atingida uma meta com essa magnitude de crescimento. Assim, mesmo havendo uma meta claramente estabelecida para o setor foi preciso utilizar outra fonte de dados para formulação do cenário. Optou-se por utilizar o crescimento real do setor Comunicações entre os anos de 1996 e 1997, a fim de captar a expansão verdadeiramente ocorrida sem superestimações. Segundo dados do IBGE, esse crescimento foi de 10,94\%, que ponderado pela participação das telecomunicações é igual a 9,56\%, sendo esse o valor que será utilizado nas simulações.

\subsubsection{Cenários de redução nos impostos}

Transporte A carga tributária incidente sobre o setor de transportes no Brasil é igual a 50,85\% como apresentado na Tabela 2. Uma carga tributária elevada implica repasse de impostos elevado para os consumidores do serviço, empresas e famílias. O repasse do imposto para frente, ou para o consumidor,

\footnotetext{
${ }^{3}$ TKU é uma medida equivalente ao transporte de uma tonelada à distância de um quilômetro.
} 
é tanto maior quanto menor for a elasticidade-preço da demanda do bem ou serviço. Como os serviços de infra-estrutura não possuem grande número de substitutos, espera-se que essa elasticidade seja pequena; assim, a transferência será elevada. Por motivo de simplificação, será usada a suposição de que toda a carga tributária é repassada para os consumidores dos serviços, estando refletida na alíquota total incidente sobre os setores produtivos pela utilização dos serviços de infra-estrutura.

Segundo estudo realizado por Amaral and Olenike (1999), a carga tributária ideal para uma empresa de serviços não deve ser superior a $15 \%$ do faturamento. A redução desse percentual será o valor utilizado na simulação.

Table 2: Carga tributária sobre o setor de transporte

\begin{tabular}{|c|c|c|c|}
\hline & Tributos & Alíquota & Base de Cálculo \\
\hline 1 & ICMS $^{1}$ & 13,73 & Receita Bruta \\
\hline 2 & ISS $^{2}$ & 3,63 & Receita Bruta \\
\hline 3 & IPTU $^{3}$ & 0,36 & Receita Bruta \\
\hline 4 & IPVA $^{4}$ & 3,16 & Receita Bruta \\
\hline 5 & CPMF $^{5}$ & 1,22 & Receita Bruta \\
\hline 6 & FGTS/Previdência $^{6}$ & 14,04 & Receita Bruta \\
\hline 7 & IRPJ $^{7}$ & 2,56 & Receita Bruta \\
\hline 8 & CSLL $^{8}$ & 0,81 & Receita Bruta \\
\hline 9 & Outros & 11,34 & Receita Bruta \\
\hline & Total de Tributos & 50,85 & \\
\hline
\end{tabular}

Fonte: Instituto Brasileiro de Planejamento Tributário IBPT (2002).

${ }^{1}$ Imposto sobre Operações relativas à Circulação de Mercadorias e sobre Prestação de Serviços de Transportes Interestaduais e Intermunicipais e de Comunicações.

2 Imposto sobre Serviços.

${ }^{3}$ Imposto Predial Territorial Urbano.

${ }^{4}$ Imposto sobre Veículos Automotores.

${ }^{5}$ Contribuição Provisória sobre Movimentação Financeira.

${ }^{6}$ Fundo de Garantia do Tempo de Serviço.

7 Imposto de Renda Pessoa Jurídica.

${ }^{8}$ Contribuição Social sobre o Lucro Líquido.

Energia elétrica A Tabela 3 mostra os impostos incidentes sobre o setor de energia elétrica, cujo somatório revela a carga tributária igual a $40,52 \%$ da receita bruta do setor. Para simulação, essa carga será reduzida à média internacional, para que o setor nacional fique em igual capacidade competitiva, em relação aos tributos, dos competidores de outros países. Para simulação, a carga tributária será reduzida para $14,44 \%{ }^{4}$

\footnotetext{
${ }^{4}$ Essa média foi calculada a partir da carga tributária sobre o setor de energia elétrica dos seguintes países: Alemanha, 13,8\%;
} EUA, 8,2\%; França, 5,2\% (Multidoc, 2005); Canadá, 15\%; e Noruega, 30\% (Bandeira, 2005). 
Table 3: Carga tributária sobre o setor de energia elétrica

\begin{tabular}{|c|c|c|c|}
\hline & Tributos & Alíquota & Base de Cálculo \\
\hline 1 & ICMS & 24,09 & Receita Bruta \\
\hline 2 & PIS $^{1}$ e COFINS ${ }^{2}$ & 6,53 & Receita Bruta \\
\hline 3 & CPMF & 0,38 & Receita Bruta \\
\hline 4 & $\mathrm{CCC}^{3}$ & 3,04 & Receita Bruta \\
\hline 5 & $\mathrm{CDE}^{4}$ & 1,6 & Receita Bruta \\
\hline 6 & P\&D/eficiência energética ${ }^{5}$ & 0,8 & Receita Bruta \\
\hline 7 & $\mathrm{ECE}^{6}$ & 2,91 & Receita Bruta \\
\hline \multirow[t]{2}{*}{8} & $\mathrm{RGR}^{7}$ & 1,15 & Receita Bruta \\
\hline & Total de Tributos & 40,52 & \\
\hline
\end{tabular}

Fonte: Teles et al. (2004).

${ }^{1}$ Programa de Integração Social.

${ }^{2}$ Contribuição para o Financiamento da Seguridade Social.

${ }^{3}$ Conta de Consumo de Combustíveis.

${ }^{4}$ Conta de Desenvolvimento Energético.

${ }^{5}$ Pesquisa e Desenvolvimento/ Eficiência Energética.

${ }^{6}$ Encargo de Capacidade Emergencial.

${ }^{7}$ Reserva Global de Reversão.

Telecomunicações A Tabela 4 ilustra os impostos que incidem sobre as telecomunicações. Assim como no setor de energia elétrica, a carga tributária de 30,38\% será reduzida ao valor da média internacional, que é de $14,34 \% .^{5}$

\subsubsection{Definição dos Cenários}

A partir dos valores acima definidos, serão simulados os cenários mostrados na Tabela 5.

\subsection{Fonte de dados}

Os dados utilizados nesta pesquisa são obtidos da Matriz de Contabilidade Social (MCS) do Brasil, elaborada a partir dos dados da Matriz de Insumo-Produto (MIP) de 1996, última matriz oficial divulgada pelo IBGE. A MIP é obtida das tabelas de insumo-produto, medidas a preços básicos, que são os preços pagos pelos consumidores depois de retiradas as margens de comércio, transportes e impostos. Os dados referentes aos encadeamentos da renda e da demanda final, ou seja, os demais dados necessários para a montagem da MCS, foram obtidos do Sistema de Contas Nacionais do IBGE e do Relatório Anual do Banco Central, no ano de 1996.

A MIP disponibilizada pelo IBGE apresenta uma desagregação de quarenta e dois setores. Nesta pesquisa, esses setores foram agregados em nove: Agropecuária, Indústria Extrativa, Indústria de Transformação, Agronegócio, Construção Civil, Transporte, Energia Elétrica, Comunicações e Serviços. A composição de cada um deles pode ser vista no Apêndice.

\footnotetext{
${ }^{5}$ Essa média foi calculada a partir da carga tributária sobre o setor de telecomunicações dos seguintes países: Itália, 20\%; Chile, 19\%; Reino Unido, 17,5\%; Espanha, 16\%; EUA, 14,2\%; Coréia, 10\%; Austrália, 10\%; e Índia, 8\% (Guerreiro, 2005).
} 
Table 4: Carga tributária sobre o setor de telecomunicações

\begin{tabular}{|c|c|c|c|}
\hline & Tributos & Alíquota & Base de Cálculo \\
\hline 1 & ICMS & 25,00 & Receita Bruta \\
\hline 2 & PIS & 0,65 & Receita Bruta \\
\hline 3 & COFINS & 3,00 & Receita Bruta \\
\hline 4 & CPMF & 0,38 & Receita Bruta \\
\hline 5 & FUST $^{1}$ & 1,00 & Receita Bruta \\
\hline 6 & FUNTELL $^{2}$ & 0,35 & $0,5 \%$ sobre Receita com Deduções \\
\hline & Total de Tributos & 30,38 & \\
\hline
\end{tabular}

Fonte: Melo and Melchior (2003).

${ }^{1}$ Fundo de Universalização dos Serviços de Telecomunicações.

${ }^{2}$ Fundo para o Desenvolvimento Tecnológico das Telecomunicações.

${ }^{3}$ Receita com Deduções calculada sem a incidência de ICMS, PIS e COFINS.

Table 5: Especificação dos cenários

\begin{tabular}{|c|c|c|c|c|c|c|}
\hline \multirow[t]{2}{*}{ Cenários } & \multicolumn{3}{|c|}{ Aumento na oferta dos serviços } & \multicolumn{3}{|c|}{ Redução nos impostos pela utilização dos serviços ${ }^{1}$} \\
\hline & $\begin{array}{c}\text { Transporte } \\
4,83 \%\end{array}$ & $\begin{array}{c}\text { Energia } \\
\text { Elétrica } \\
5,32 \% \\
\end{array}$ & $\begin{array}{c}\text { Telecomuni- } \\
\text { cações } \\
9,57 \% \\
\end{array}$ & $\begin{array}{c}\text { Transporte } \\
\text { De } 50,85 \% \\
\text { para } 15 \% \\
\end{array}$ & $\begin{array}{c}\text { Energia Elétrica } \\
\text { De } 40,52 \% \\
\text { para } 14,44 \% \\
\end{array}$ & $\begin{array}{c}\text { Telecomunicações } \\
\text { De } 30,38 \% \\
\text { para } 14,34 \% \\
\end{array}$ \\
\hline 1 & $\mathrm{X}$ & $\mathrm{X}$ & $\mathrm{X}$ & & & \\
\hline 2 & & & & $\mathrm{X}$ & $\mathrm{x}$ & $\mathrm{X}$ \\
\hline 3 & $\mathrm{X}$ & $\mathrm{X}$ & $\mathrm{X}$ & $\mathrm{X}$ & $\mathrm{X}$ & $\mathrm{x}$ \\
\hline
\end{tabular}

Fonte: Dados da pesquisa.

${ }^{1}$ Os valores indicados representam a carga tributária dos setores. Por simplificação, nesses cenários será utilizada a suposição que essa carga seja totalmente repassada para os consumidores dos serviços, refletindo-se nas alíquotas pagas pelos setores consumidores, obtida na MIP.

Para obtenção dos dados referentes ao setor de energia elétrica, não disponível na MIP, foi desagregada do setor de Serviços Industriais de Utilidade Pública (SIUP) uma proporção de $80 \%$ do seu valor total. Segundo informações do IBGE, essa é a proporção do serviço de energia elétrica, dentre os serviços que compõem o SIUP.

Embora na formulação do cenário de aumento na oferta tenham sido levados em consideração os diferentes modais de transporte, esse setor será tratado de forma agregada, como disponibilizado na MIP. A não-obtenção de dados impossibilitou que essa desagregação fosse realizada.

Na construção do algoritmo, para obtenção do equilíbrio inicial do sistema de equações e simulações de cenários, foi utilizado o software Mathematical Programming System for General Equilibrium (MPSGE), desenvolvido na Universidade do Colorado, nos Estados Unidos, por Thomas F. Rutherford. O MPSGE consiste em uma linguagem de programação específica para formulação e análise de modelos de equilíbrio geral, no qual o equilíbrio competitivo é definido pelo conjunto de equações não-lineares (Vieira, 1997).

As elasticidades de substituição $\left(\sigma_{i}^{s}\right)$ e de transformação $\left(\sigma_{i}^{t}\right)$, necessárias para calibração do MAEG, foram obtidas de Oliveira (2002); as propensões marginais a consumir $\left(\tau_{f}\right)$ e a poupar $\left(v_{f}\right)$, de Vieira 
(1998); e as tarifas de exportação e importação, de Domingues and Lemos (2004) e da MIP, respectivamente. Os valores desses parâmetros e tarifas estão apresentados no Apêndice nas Tabelas 13 a 15.

Através das elasticidades de substituição $\left(\sigma_{i}^{s}\right)$ e de transformação $\left(\sigma_{i}^{t}\right)$ foram obtidos os parâmetros de substituição $\left(\rho_{i}^{s}\right)$ e transformação $\left(\rho_{i}^{t}\right)$ que possuem as seguintes relações: $:^{6} \rho_{i}^{s}=\frac{1-\sigma_{i}^{s}}{\sigma_{i}^{s}}$ e $\rho_{i}^{t}=\frac{1-\sigma_{i}^{t}}{\sigma_{i}^{t}}$. Os parâmetros tecnológicos das funções CES $\left(\epsilon_{i}\right)$ e CET $\left(\beta_{i}\right)$, bem como os parâmetros de distribuição dessas funções $\left(\delta_{i}\right.$ e $\gamma_{i}$ ) foram calculados a partir dos valores observados na MCS dos fatores capital e trabalho e valor adicionado, de acordo com as relações apresentadas na equação (2), e dos valores observados das exportações, vendas domésticas e produção doméstica, conforme relação apresentada na equação (5).

O parâmetro de produtividade $\left(\alpha_{i j}\right)$ foi obtido pela divisão dos valores do consumo intermediário pela produção doméstica de cada setor analisado. O parâmetro do índice de preço $\left(z_{i},\right)$, o numerário do modelo, foi obtido pela divisão do valor do consumo das famílias em cada setor pelo total do consumo das famílias.

Esses parâmetros foram verificados por meio da calibração, que consiste em avaliar as adequações deles na determinação de uma solução inicial para o sistema de equações do modelo, de modo que as equações sejam satisfeitas pelos valores do equilíbrio inicial. Uma vez calibrado, é possível verificar como se comportam as variáveis do modelo, em decorrência de um choque.

\section{RESULTADOS}

O Cenário 1 apresenta os resultados do aumento na oferta total dos serviços de infra-estrutura. Como conseqüência do choque, os próprios setores de transporte, energia elétrica e comunicações são os que apresentariam maior acréscimo no nível de atividade, tanto em termos percentuais quanto em termos absolutos (Tabela 6). Dentre os demais setores, os aumentos mais elevados estariam na indústria de transformação e comércio e serviços. $O$ crescimento agregado do nível de atividade produtiva seria igual a 3,36\% (Tabela 6).

Table 6: Variação percentual e absoluta no nível de atividade, devido ao aumento na oferta dos serviços de infra-estrutura e redução nos impostos

\begin{tabular}{|l|ccc|ccc|}
\hline & \multicolumn{3}{|c|}{ Variação percentual } & \multicolumn{3}{c|}{ Variação absoluta (RS Milhões) } \\
\cline { 2 - 7 } & Cenário 1 & Cenário 2 & Cenário 3 & Cenário 1 & Cenário 2 & Cenário 3 \\
\hline Agropecuária & $0,44 \%$ & $-0,01 \%$ & $0,43 \%$ & 423,87 & $-5,43$ & 414,86 \\
Indústria Extrativa & $2,25 \%$ & $0,07 \%$ & $2,32 \%$ & 661,89 & 19,88 & 682,48 \\
Ind. de Transf. & $2,58 \%$ & $0,05 \%$ & $2,66 \%$ & $8.580,55$ & 175,76 & $8.842,75$ \\
Agroindústria & $1,03 \%$ & $0,01 \%$ & $1,04 \%$ & $1.081,33$ & 9,03 & $1.091,39$ \\
Construção civil & $1,22 \%$ & $0,01 \%$ & $1,23 \%$ & $1.350,88$ & 9,61 & $1.366,90$ \\
Transportes & $18,94 \%$ & $0,43 \%$ & $19,53 \%$ & $8.512,18$ & 194,75 & $8.778,41$ \\
Energia elétrica & $31,18 \%$ & $2,54 \%$ & $34,80 \%$ & $8.429,36$ & 686,43 & $9.407,94$ \\
Comunicações & $42,41 \%$ & $0,28 \%$ & $42,88 \%$ & $7.059,82$ & 47,2 & $7.138,39$ \\
Comércio e Serviços & $1,35 \%$ & $0,03 \%$ & $1,40 \%$ & $7.080,92$ & 150,4 & $7.340,97$ \\
Total & $3,36 \%$ & $0,10 \%$ & $3,50 \%$ & $43.180,81$ & $1.287,65$ & $45.064,09$ \\
\hline
\end{tabular}

Fonte: Resultados da pesquisa.

\footnotetext{
${ }^{6}$ A derivação das relações entre esses parâmetros pode ser verificada em Chiang (1982) e Oliveira (2006).
} 
A simulação da redução dos impostos é apresentada no Cenário 2. Como pode-se perceber, as variações resultantes desse choque são inferiores aos obtidos no Cenário 1, entretanto, não são insignificantes, como se pode verificar pelas variações absolutas. Assim como no Cenário 1, também neste os maiores acréscimos no nível de atividade seriam observados nos setores de infra-estrutura. De forma agregada, a atividade produtiva da economia cresceria $0,1 \%$ ou $\mathrm{R} \$ 1.287,65$ milhões. As indústrias extrativa e de transformação, após os setores de infra-estrutura, obteriam os maiores crescimentos percentuais, enquanto em termos absolutos seriam a indústria de transformação, e comércio e serviços que cresceriam mais até mesmo do que comunicações, um setor de infra-estrutura. Apenas a agropecuária apresentaria redução no nível de atividade nesse cenário (Tabela 6), a qual poderia ser explicada pelo fato de existirem complementaridade e substitutibilidade entre os bens e pela existência de quantidade fixa de fatores.

No Cenário 3, é simulado o aumento na oferta dos setores de infra-estrutura e redução nos impostos incidentes sobre o uso dos serviços prestados por esses setores, simultaneamente. Como resultado dessa política, haveria expansão no valor da produção de todos os setores, e a atividade produtiva brasileira experimentaria um crescimento de 3,5\% (Tabela 6). O comportamento dos setores, separadamente, seria semelhante ao observado no Cenário 1 , dada a relevância da expansão dos serviços de infra-estrutura (Cenário 1) na composição do Cenário 3.

A Tabela 7 mostra o comportamento dos preços domésticos nos três cenários simulados. Os preços dos serviços de transporte, energia elétrica e comunicações seriam reduzidos, nos Cenários 1 e 3 . No Cenário 2, nem todos os produtos teriam variação no preço; e caso houvesse variações, estas seriam muito pequenas. Haveria redução nos preços da indústria extrativa, transporte e energia elétrica, nesse cenário.

A participação dos custos com os serviços de infra-estrutura no total de custos com consumo intermediários é apresentada na Tabela 4, para equilíbrio inicial (benchmark) e Cenários 1, 2 e 3. Os custos com serviços de transporte têm o maior percentual na maioria dos setores no equilíbrio inicial, exceto em energia elétrica. No Cenário 1, a redução nos preços dos serviços de infra-estrutura, devido ao aumento da oferta desses serviços, ocasionaria redução nos custos para os setores produtivos. Observa-se, neste cenário, que os próprios setores de infra-estrutura obteriam maior redução nos custos, resultante da política de aumento na oferta, o que possibilitaria a prestação do serviço a menor preço. A participação dos custos de transporte no próprio setor cairia de 23,6\% para 22,42\%. Dentre os demais setores o maior impacto seria na indústria extrativa, em que o custo total (coluna 5) com os serviços de infraestrutura cairia de 17,90\% para 16,95\%; comércio e serviço e indústria de transformação apresentariam redução de $12,70 \%$ para $11,95 \%$ e de $12,20 \%$ para $11,52 \%$ respectivamente, em relação ao equilíbrio inicial.

Na Tabela 8, pode-se observar que comparando o Cenário 2 e o benchmark a redução nos custos seria muito pequena. Isso ocorreria devido ao pequeno impacto que a política de redução tributária teria nos preços dos serviços de infra-estrutura. No Cenário 3, as reduções nos custos seriam semelhantes às do Cenário 1 , já que a expansão dos serviços de infra-estrutura teriam os maiores impactos na redução dos custos.

O aumento na produção, aliado ao ganho de competitividade, obtidos por alguns setores com redução de preços, elevaria as exportações em todos os cenários. Enquanto as exportações teriam elevação expressiva, as importações cairiam, o que implicaria melhora na balança comercial e, conseqüentemente, na obtenção de divisas (Tabela 9). Melhores condições da infra-estrutura nacional e redução na carga tributária do setor produtivo elevariam, portanto, a obtenção de ganhos com o comércio exterior.

O aumento nas exportações também poderia ser apontado como um fator explicativo da elevação nos preços dos setores agropecuária, agroindústria, construção civil e comércio e serviços, conforme Tabela 7, pois reduziria a oferta interna dos bens.

$\mathrm{O}$ crescimento da economia, dado pelo aumento da oferta de serviços de infra-estrutura, está apresentado no Cenário 1, na Tabela 9. O PIB apresentaria crescimento significativo, o que evidenciaria a relação positiva entre quantidade e qualidade de infra-estrutura e crescimento econômico. Esse re- 
Table 7: Variação percentual nos preços devido ao aumento na oferta de serviços de infra-estrutura e à redução dos impostos

\begin{tabular}{|l|c|c|c|}
\hline & Cenário 1 & Cenário 2 & Cenário 3 \\
\hline Agropecuária & $0,67 \%$ & $0,02 \%$ & $0,68 \%$ \\
Indústria Extrativa & $0,06 \%$ & $0,00 \%$ & $0,05 \%$ \\
Ind. de Transformação & $0,07 \%$ & $0,00 \%$ & $0,07 \%$ \\
Agroindústria & $0,41 \%$ & $0,01 \%$ & $0,42 \%$ \\
Construção civil & $0,69 \%$ & $0,02 \%$ & $0,71 \%$ \\
Transportes & $-4,63 \%$ & $-0,04 \%$ & $-4,67 \%$ \\
Energia elétrica & $-5,52 \%$ & $-0,43 \%$ & $-5,90 \%$ \\
Comunicações & $-8,06 \%$ & $0,02 \%$ & $-8,04 \%$ \\
Comércio e Serviços & $0,58 \%$ & $0,01 \%$ & $0,59 \%$ \\
\hline
\end{tabular}

Fonte: Resultados da pesquisa.

Table 8: Participação relativa do custo com os serviços de infra-estrutura no consumo intermediário dos setores produtivos, no equilíbrio inicial e nos cenários 1,2 e 3

\begin{tabular}{|c|c|c|c|c|c|c|c|c|c|c|}
\hline & \multicolumn{4}{|c|}{ Benchmark $^{1}$} & \multicolumn{4}{|c|}{ Cenário 1} & \multirow{2}{*}{$\begin{array}{l}\text { Cenário } \\
2 \\
\text { Total } \\
\end{array}$} & \multirow{2}{*}{$\begin{array}{l}\text { Cenário } \\
3 \\
\text { Total } \\
\end{array}$} \\
\hline & Trans & Energia & Telecom & Total & Trans & Energia & Telecom & Total & & \\
\hline Agropecuária & $5,60 \%$ & $1,04 \%$ & $0,10 \%$ & $6,74 \%$ & $5,34 \%$ & $0,99 \%$ & $0,09 \%$ & $6,41 \%$ & $6,73 \%$ & $6,41 \%$ \\
\hline Indústria Extrativa & $9,38 \%$ & $6,78 \%$ & $1,74 \%$ & $17,90 \%$ & $8,95 \%$ & $6,41 \%$ & $1,60 \%$ & $16,95 \%$ & $17,87 \%$ & $16,92 \%$ \\
\hline Ind. de Transform. & $5,84 \%$ & $4,37 \%$ & $1,99 \%$ & $12,20 \%$ & $5,57 \%$ & $4,13 \%$ & $1,83 \%$ & $11,52 \%$ & $12,17 \%$ & $11,51 \%$ \\
\hline Agroindústria & $2,95 \%$ & $1,18 \%$ & $0,58 \%$ & $4,70 \%$ & $2,81 \%$ & $1,11 \%$ & $0,53 \%$ & $4,46 \%$ & $4,70 \%$ & $4,45 \%$ \\
\hline Construção civil & $5,06 \%$ & $0,48 \%$ & $0,90 \%$ & $6,45 \%$ & $4,83 \%$ & $0,46 \%$ & $0,83 \%$ & $6,12 \%$ & $6,45 \%$ & $6,11 \%$ \\
\hline Transportes & $23,58 \%$ & $0,77 \%$ & $2,46 \%$ & $26,81 \%$ & $22,48 \%$ & $0,73 \%$ & $2,26 \%$ & $25,48 \%$ & $26,80 \%$ & $25,47 \%$ \\
\hline Energia elétrica & $0,83 \%$ & $50,38 \%$ & $0,52 \%$ & $51,73 \%$ & $0,79 \%$ & $47,60 \%$ & $0,48 \%$ & $48,87 \%$ & $51,51 \%$ & $48,67 \%$ \\
\hline Comunicações & $9,16 \%$ & $0,04 \%$ & $3,95 \%$ & $13,15 \%$ & $8,74 \%$ & $0,03 \%$ & $3,63 \%$ & $12,40 \%$ & $13,15 \%$ & $12,40 \%$ \\
\hline Comér. e Serviços & $4,85 \%$ & $4,36 \%$ & $3,50 \%$ & $12,70 \%$ & $4,62 \%$ & $4,12 \%$ & $3,22 \%$ & $11,95 \%$ & $12,68 \%$ & $11,94 \%$ \\
\hline
\end{tabular}

Fonte: Resultados da pesquisa. "Trans" é abreviatura para "Transporte”, “Telecom" para "telecomunicações" e "Energia” para "Energia elétrica".

${ }^{1}$ Refere-se aos custos do ano de 1996, obtidos da MCS. 
Table 9: Variação percentual em variáveis macroeconômicas selecionadas, devido ao aumento na oferta dos serviços de infra-estrutura e à redução nos impostos

\begin{tabular}{|l|c|c|c|}
\hline & Cenário 1 & Cenário 2 & Cenário 3 \\
\hline Importações & $-0,05 \%$ & $0,00 \%$ & $-0,05 \%$ \\
Exportações & $0,52 \%$ & $0,02 \%$ & $0,53 \%$ \\
Arrecadação de impostos & $2,05 \%$ & $-0,03 \%$ & $2,03 \%$ \\
Investimento & $1,21 \%$ & $0,01 \%$ & $1,22 \%$ \\
Preço do Capital & $0,96 \%$ & $0,02 \%$ & $0,99 \%$ \\
Preço do Trabalho & $1,02 \%$ & $0,03 \%$ & $1,06 \%$ \\
PIB & $1,00 \%$ & $0,01 \%$ & $1,02 \%$ \\
\hline
\end{tabular}

Fonte: Resultados da pesquisa.

sultado confirma o obtido por Ferreira and Malliagros (1998), que identificaram forte relação de longo prazo entre infra-estrutura e crescimento do PIB. Nesse cenário, o crescimento do PIB seria de $1 \%$. A desoneração tributária dos setores produtivos, com redução nos impostos incidentes sobre o uso dos serviços de infra-estrutura no Cenário 2, também implicaria crescimento da economia brasileira, porém o aumento do PIB seria pequeno, comparado ao obtido no cenário anterior.

Em todos os cenários, haveria crescimento na remuneração aos fatores capital e trabalho, reflexo da maior demanda por uma quantidade fixa de fatores devido ao aumento na atividade produtiva.

A elevação na remuneração aos fatores elevaria a renda das famílias, uma vez que são proprietárias desses fatores. O aumento na renda implicaria elevação no consumo das famílias, com acréscimo das duas variáveis quase na mesma proporção (Tabela 10). O crescimento no consumo das famílias também poderia ser um fator responsável pelo crescimento dos preços, que seria observado na maioria dos setores, pois aumento nas exportações e no consumo sem elevação das importações, simultaneamente, geraria uma pressão de demanda, levando ao crescimento dos preços.

Table 10: Variação percentual na renda e consumo das famílias, devido ao aumento na oferta dos serviços de infra-estrutura e à redução dos impostos

\begin{tabular}{|l|c|c|c|}
\hline & Cenário 1 & Cenário 2 & Cenário 3 \\
\hline Renda & $1,33 \%$ & $0,01 \%$ & $1,34 \%$ \\
Consumo & $1,16 \%$ & $0,01 \%$ & $1,17 \%$ \\
\hline
\end{tabular}

Fonte: Resultados da pesquisa.

Como a arrecadação de impostos a única fonte de receita do Governo no modelo, a redução nos tributos implicaria menor arrecadação no Cenário 2 (Tabela 9), mas a expansão da economia, obtida no Cenário 1 , traria elevação na receita do Governo. Com a implementação das duas políticas simultaneamente, Cenário 3, a arrecadação tributária não seria prejudicada, pois a expansão da economia, ou seja, do montante tributado, dado o crescimento da renda, das exportações e da produção, traria ganho de 
receita para o Governo que compensaria o efeito negativo da redução nas alíquotas incidentes sobre o uso dos serviços de infra-estrutura (Tabela 9).

Com o aumento da renda, da arrecadação tributária e das exportações haveria crescimento do investimento, dando continuidade ao processo de crescimento econômico (Tabela 9).

Table 11: Efeitos do aumento na oferta dos serviços de infraestrutura e da redução nos impostos sobre o bem-estar (R\$ mil)

\begin{tabular}{|c|c|}
\hline & Variação Equivalente \\
\hline Cenário 1 & $7.764,40$ \\
Cenário 2 & 58,17 \\
Cenário 3 & $7.859,74$ \\
\hline
\end{tabular}

${ }^{a}$ Fonte: Resultados da pesquisa.

Os ganhos de bem-estar estão apresentados na Tabela 11. O valor positivo da variação equivalente revela que o nível de satisfação dos consumidores se elevaria com o aumento da oferta de serviços de infra-estrutura e com a redução nos impostos incidentes sobre eles, ou seja, mediante essa política, tanto o setor produtivo quanto os consumidores seriam beneficiados. Os valores apresentados nesta tabela representariam os ganhos dos consumidores, caso as políticas fossem implementadas ou, por outro lado, representariam o quanto a sociedade brasileira perderia devido à precariedade e ineficiência da infra-estrutura nacional e à elevada carga tributária.

\section{CONCLUSÕES}

As políticas de aumento na oferta de serviços de infra-estrutura e de redução nos impostos incidentes sobre o seu uso levariam ao crescimento do nível de atividade agregado. Os setores transporte, energia elétrica e comunicações, em que os choques foram simulados, apresentariam os maiores crescimentos e, dentre os demais, indústria de transformação, e comércio e serviços.

Como resultado das políticas, os preços dos serviços de infra-estrutura seriam reduzidos; assim, o custo de utilização deles pelo setor produtivo também seria reduzido. Dessa forma, as políticas confeririam maior competitividade aos setores produtivos nacionais.

Com o setor produtivo mais competitivo, haveria crescimento das exportações. As importações apresentariam variações pequenas e negativas, na maioria dos casos simulados. Assim, conclui-se que essas políticas teriam um efeito benéfico sobre a balança comercial.

A implementação dessas políticas elevaria a remuneração aos fatores capital e trabalho, o que implicaria elevação na renda e no consumo das famílias.

A política de redução tributária, como esperado, levaria à redução na receita do Governo. Entretanto, a expansão da economia, dada principalmente pelo aumento da oferta de serviços de infra-estrutura, elevaria a arrecadação tributária e mais que compensaria a redução conseqüente da política de redução tributária. Dessa forma, a combinação das duas políticas elevaria a competitividade do setor produtivo, sem prejudicar o orçamento do setor público. Com implementação das políticas, o PIB apresentaria taxas de crescimento positivas e mais significativas em resposta à política de aumento de oferta de serviços na infra-estrutura. Haveria, ainda, ganho de utilidade para os consumidores, ou seja, a economia seria beneficiada como um todo. 
Políticas que colaboram para redução nos custos com serviços de infra-estrutura tornam os setores econômicos mais produtivos e competitivos e dão grande impulso ao crescimento e à promoção do bem-estar social. Sugere-se, em trabalhos futuros, desagregação dos setores mais impactados, como a indústria de transformação, para análise detalhada dos impactos e recomendação de políticas.

Pode-se apontar, como limitação desta pesquisa, a não-desagregação dos modais do setor de transporte, essa desagregação seria interessante, pois o modal rodoviário destaca-se entre os demais. Superada essa limitação, seria possível, por exemplo, simular mudanças nas participações dos modais na matriz de transporte de cargas do Brasil. Os resultados obtidos nesta pesquisa contribuem para discussão dos impactos da ineficiência da infra-estrutura na economia nacional, considerando as interligações setoriais, e revelam os desdobramentos de políticas necessárias.

\section{BIBLIOGRAPHY}

Agência Nacional de Telecomunicações, A. (2005). Perspectiva para ampliação e modernização do setor de telecomunicações (PASTE) 2000-2005. Disponível em: http://www.anatel.gov.br/ Tools/frame.asp?link=/indicadores/telemapa/dados_brasil_paste.pdf. Acesso em: 16 dez. 2005.

Agência Nacional de Transportes Aquaviários, A. (2005). Anuário estatístico 2005. Disponível em: http: //www . antaq.gov.br/PortalPortos/Estatistica\%20Anuarios.htm. Acesso em: 9 jan. 2006.

Agência Nacional de Transportes Terrestres, A. (2006). Desempenho portuário - indicadores de desempenho operacional. Disponível em: http://www . antaq.gov . br/IndexPortos . asp. Acesso em: 5 jan. 2006.

Amaral, G. L. \& Olenike, J. E. (1999). Pesquisa revela carga tributária ideal para competitividade das empresas. Instituto Brasileiro de Planejamento Tributário (IBPT), 1999. Disponível em: http://www.ibpt.com.br/arquivos/artigos/PESQUISA_REVELA_CARGA_TRIBUTARIA_ IDEAL_PARA.doc. Acesso em: 30 jan. 2006.

Aschauer, D. A. (1989). Is public expenditure productive? Journal of Monetary Economics, 23:177-200.

Banco Da Amazônica (BASA) (2004). Matriz insumo-produto da amazônia e dos estados da região. Belém, 2004 (CD-ROM).

Bandeira, F. P. M. (2005). Avaliação do preço da energia elétrica para o consumidor direto brasileiro. Brasília: Consultoria Legislativa, 2003. 10 p. (Nota Técnica). Disponível em: http://www . camara. gov.br/internet/diretoria/\%20Conleg/Notas/2003_5668.pdf. Acesso em: 3 dez. 2005.

Bernard, A. B. \& Garcia, M. G. P. (1995). Provisão pública e privada da infra-estrutura e desenvolvimento econômico. Rio de Janeiro: BNDES, 1995. (Texto para Discussão n. 32).

Braga, M. J. (1999). Reforma fiscal e desenvolvimento das cadeias agroindustriais. Tese (Doutorado em Economia Rural) - Universidade Federal de Viçosa, 1999.

Carvalho, P. G. (2004). Novas teorias do crescimento endógeno. Que indicadores? CovilhaPortugal: Universidade da Beira Interior, 2004. Disponível em:http://www.ubi.pt/pguedes/ Ntcresendogeno. Acesso em: 26 nov. 2004.

Chiang, A. C. (1982). Matemática Para Economistas. McGrraw-Hill, São Paulo.

Confederação Nacional Dos Transportes (CNT) (2005). Boletim estatístico CNT. 
de Minas e Energia (MME), M. (2005). Balanço energético nacional 2005. Disponível em: http:// www.mme.gov.br/site/menu/select_main_menu_item.do?channelId=1432\&pageId=4123. Acesso em: 9 jan. 2006.

Domingues, E. P. \& Lemos, M. B. (2004). Regional impacts of trade liberalization strategies in Brazil. Belo Horizonte: UFMG/CEDEPLAR, 2004. 31 p. (Texto para Discussão n. 234).

Dumont, J. C. \& Mesplé-Somps, S. (2000). The impact of public infrastructure on competitiveness and growth: A CGE analisis applied to Senegal. Quebec- Canadá: Centre de Recherch en économie et finance appliqués, 2000. . (Cahier n. 15). Disponível em: http://www.crefa.ecn.ulaval.ca/ cahier/0015.pdf. Acesso em: 04 out. 2005.

Ferreira, P. C. (1996). Investimento em infra-estrutura no Brasil: Fatos estilizados e relações de longo prazo. Pesquisa e Planejamento Econômico, 26(2):231-252.

Ferreira, P. C. \& Malliagros, T. G. (1998). Impactos produtivos da infra-estrutura no Brasil: 1950-1995. Pesquisas e Planejamento Econômico, 2:315-338.

Ferreira, P. C. \& Nascimento, L. G. (2006). Welfare and growth effects of alternative fiscal rules for infrastructure investment in Brazil. Rio de Janeiro: FGV, 2006. Disponível em: http://www. econ. puc-rio.br/pdf/seminario/2006/pedro. cavalcanti.pdf. Acesso em: 15 abr. 2009.

Ferreira Filho, J. B. S. (1998). Introdução aos modelos aplicados de equilíbrio geral: Conceitos, teorias e aplicações. Piracicaba: ESALQ, 1998. 41 p. (Série Didática n. 120).

Filelline, A. (1989). Economia Do Setor Público. Atlas, São Paulo.

Fochezatto, A. (2002). Testando um modelo de equilíbrio geral computável para a economia gaúcha: Impactos da reestruturação tributária. In Encontro de Economia Gaúcha, 1., 2002, Porto Alegre-RS. FEE, Porto Alegre. Disponível em: http://www.fee.tche.br/sitefee/download/eeg/1/\%20mesa_ 5_fochezatto.pdf. Acesso em: 11 nov. 2004.

Guerreiro, R. (2005). (tele) comunicações 2015: Contribuições para o aperfeiçoamento do modelo. Guerreiro Teleconsult, 2005. Disponível em: http://www.telebrasil.org.br/arquivos/ telebrasil\_sumario\_executivo\_futurecom.doc. Acesso em: 30 jan. 2005.

Hirschman, A. (1983). Confissões de um dissidente: A estratégia do desenvolvimento. Pesquisa e planejamento econômico, 13(1):1-37.

Instituto Brasileiro de Planejamento Tributário - IBPT (2002). Realidade tributária brasileira. Curitiba-PR: IBPT,2002.

Lima, E. T., Nassif, A. L., \& Carvalho Júnior, M. C. (1997). Infra-estrutura, diversificação das exportações e redução do Custo-Brasil: Limites e possibilidades. Revista do BNDES, (704):1-29.

Lírio, V. S. (2001). Do Mercosul à Alca: Impactos sobre o CAI brasileiro. Tese (Doutorado em Economia Rural) - Universidade Federal de Viçosa, 2001.

Martins, R. S. (2004). Fretes rodoviários do agronegócio nos principais corredores de exportação no Brasil: Diferenciação regional, sazonalidade e integração de mercados. CNPq. Projeto de Pesquisa.

Martone, C. L., Silber, S. D., \& Sockun, M. H. (2004). Políticas para reduzir a vulnerabilidade externa do Brasil. São Paulo: FIESP, 2004. (Referências FIESP 6). Disponível em: http://www.fiesp.com.br/ download/publicacoes_economia/referencias_6.pdf. Acesso em: 28 nov. 2004. 
Melo, J. B. \& Melchior, S. (2003). Tributação sobre serviços de telecomunicações. Disponível em: http: //www.teleco.com.br/tutoriais/tutorialtrib/default. asp. Acesso em: 17 jan. 2006.

Mendes, V. \& Vale, S. (2001). O modelo de Solow: Equilíbrio de longo prazo. Lisboa-PT: Instituto Superior de Ciências do Trabalho e da Empresa, 2001. (Texto Base Macroeconomia n. 14). Disponível em: http: //iscte.pt/MacroEconomia/CapSolow1.pdf. Acesso em: 27 nov. 2004.

Ministério do Planejamento, O. e. G. M. (2003). Mensagem ao congresso nacional 2003. Disponível em: http://www.presidencia.gov.br/publi_04/COLECAO/mens03_06.pdf. Acesso em: 29 ago. 2004.

Multidoc (2005). Impostos no Brasil. Disponível em: http://www.multidoc.com.br/sobr/imp. htm. Acesso em: 31 out. 2005.

Oliveira, J. C. V. d. (2002). Sobrevalorização da taxa de câmbio e o agronegócio: Uma análise de equilíbrio geral com base na estrutura produtiva brasileira de 1995. Tese de Doutorado. Piracicaba: ESALQ, 2002. $173 \mathrm{p}$.

Oliveira, M. A. S. (2006). Aumento da oferta e redução de impostos nos serviços de infra-estrutura na economia brasileira: Uma abordagem de equilíbrio geral. Tese de Doutorado. Viçosa: UFV, 2006. 137 p.

Pereira, C. M. \& Araújo, J. T. (1997). Crescimento econômico: Uma resenha da literatura. In Fontes, R., editor, Estabilização e Crescimento, page 410. UFV, Viçosa.

Ponciano, N. J. (2000). Ajustamento na política comercial brasileira e seus efeitos nas cadeias agroindustriais. Tese de Doutorado em Economia Rural - Universidade Federal de Viçosa, 2000.

Sadoulet, E. \& De Janvry, A. (1995). Quantitative Developmente Policy Analysis. Johns Hopkins University, London.

Schroeder, E. M. \& Castro, J. C. (1996). Transporte rodoviário de cargas: Situação atual e perspectivas. Revista do BNDES, dez. 1996. disponível em: http://www. bndes.gov.br/conhecimento/ revista/carga.pdf. Acesso em: 21 abr. 2006.

Smith, A. (1981). Uma Investigação Sobre a Natureza e Causas Das Riquezas Das Nações. Hemus, São Paulo.

Souza, N. J. d. (1995). Desenvolvimento Econômico. Atlas, São Paulo.

Suzigan, W. \& Fernandes, S. C. (2003). Competitividade sistêmica: A contribuição de Fernando Fajnzylber. In Congresso Brasileiro de História Econômica. ABPHE, Caxambu-MG. Disponível em: http://www . abphe.org.br/congresso2003/Textos/Abphe_2003_15.pdf. Acesso em: 31 out. 2005.

Teles, W. R., Bento, S., \& Mutinelli, E. (2004). Estudo do novo modelo do setor elétrico brasileiro. SL: PricewaterhouseCoopers, 2004. 51p. Disponível em: http://www.pwc.com/images/bz/Modelo_ setor_eletrico_04.pdf. Acesso em: 6 jan. 2006.

Varian, H. R. (1993). Intermediate Microeconomics. Norton, New York, 3 edition.

Vieira, W. C. (1997). Modelos aplicados de equilibrio peral: Formulação e análise utilizando-se o MPSGE. Economia Rural, 8(4):22-27.

Vieira, W. C. (1998). Notas sobre a construção de matrices de contabilidade social. Economia Rural, 9(2):30-37.

\section{A. TABELAS}


Table A-1: Agregação da matriz de insumo-produto

\begin{tabular}{|c|c|c|}
\hline & Agregação da pesquisa & Agregação IBGE \\
\hline 1 & Agropecuária & Agropecuária \\
\hline 2 & Indústria Extrativa & $\begin{array}{l}\text { Extrativa mineral; Extração de petróleo e gás; } \\
\text { Minerais não-metálicos. }\end{array}$ \\
\hline 3 & Ind. de Transformação & $\begin{array}{l}\text { Siderurgia; metalurgia de não-ferrosos; Out- } \\
\text { ros metalúrgicos; Máquinas e tratores; Material } \\
\text { elétrico; Equipamentos eletrônicos; Automóveis, } \\
\text { caminhões e ônibus; Outros veículos e peças; } \\
\text { Madeira e mobiliário; Papel e gráfica; Indústria da } \\
\text { borracha; Elementos químicos; Refino do petróleo; } \\
\text { Outros produtos químicos; Farmacêutica e de per- } \\
\text { fumaria; Artigos de plástico; Indústria têxtil; Arti- } \\
\text { gos do vestuário; Fabricação de calçados; Produtos } \\
\text { diversos. }\end{array}$ \\
\hline 4 & Agroindústria & $\begin{array}{l}\text { Indústria do café; Beneficiamento de produtos } \\
\text { vegetais; Abate de animais; Indústria de laticínios; } \\
\text { Indústria do açúcar; Fabricação de óleos vegetais; } \\
\text { Outros produtos alimentares. }\end{array}$ \\
\hline 5 & Construção civil & Construção civil \\
\hline 6 & Transporte & Transporte \\
\hline 7 & Energia elétrica & Serviços industriais de utilidade pública \\
\hline 8 & Comunicações & Comunicações \\
\hline 9 & Demais serviços & $\begin{array}{l}\text { Serviços industriais de utilidade pública (exceto } \\
\text { energia elétrica); Comércio; Instituições finan- } \\
\text { ceiras; Serviços prestados às famílias; Serviços } \\
\text { prestados às empresas; Aluguel de imóveis; } \\
\text { Administração pública; Serviços privados não- } \\
\text { mercantis. }\end{array}$ \\
\hline
\end{tabular}


Table A-2: Elasticidades de substituição e de transformação

\begin{tabular}{|l|c|c|}
\hline \multicolumn{1}{|c|}{ Setores } & $\begin{array}{c}\text { Elasticidade de Substituição } \\
\left(\sigma_{i}^{s}\right)\end{array}$ & $\begin{array}{c}\text { Elasticidade de Transformação } \\
\left(\sigma_{i}^{t}\right)\end{array}$ \\
\hline Agropecuária & 0,90 & 1,50 \\
\hline Indústria extrativa & 1,30 & 0,80 \\
\hline Ind. de transformação & 1,70 & 2,00 \\
\hline Agroindústria & 0,89 & 1,50 \\
\hline Construção civil & 0,90 & 0,90 \\
\hline Transportes & 1,30 & 1,10 \\
\hline Energia elétrica & 0,90 & 1,10 \\
\hline Comunicações & 1,10 & 1,10 \\
\hline Comércio e serviços & 1,10 & 1,10 \\
\hline
\end{tabular}

: Fonte: Oliveira (2002).

Table A-3: Tarifas sobre exportações e importações brasileiras - 1996

\begin{tabular}{|l|c|c|}
\hline \multicolumn{1}{|c|}{ Setores } & $\begin{array}{c}\text { Tarifas sobre Exportações } \\
\left(t_{i}^{x}\right)\end{array}$ & $\begin{array}{c}\text { Tarifas sobre Importações } \\
\left(t_{i}^{m}\right)\end{array}$ \\
\hline Agropecuária & $3,842 \%^{1}$ & $2,04 \%$ \\
\hline Indústria extrativa & $5,807 \%^{1}$ & $13,85 \%$ \\
\hline Ind. de transformação & $5,404 \%^{1}$ & $61,81 \%$ \\
\hline Agroindústria & $20,537 \%^{1}$ & $2,79 \%$ \\
\hline Construção civil & $1,000 \%^{2}$ & $0,00 \%$ \\
\hline Transportes & $1,063 \%^{2}$ & $0,00 \%$ \\
\hline Energia elétrica & $1,063 \%^{2}$ & $0,00 \%$ \\
\hline Comunicações & $1,063 \%^{2}$ & $0,17 \%$ \\
\hline Comércio e serviços & $1,063 \%^{2}$ & $0,84 \%$ \\
\hline
\end{tabular}

${ }^{1}$ Domingues and Lemos (2004).

2 Lírio (2001).

${ }^{3}$ MIP, Tabela 9 - Destino do imposto sobre importação em 1996.

Table A-4: Propensões marginais a poupar e a consumir das famílias

$$
\begin{array}{|l|l|}
\hline \text { Propensão marginal a poupar }\left(\vartheta_{f}\right) & 0,40 \\
\text { Propensão marginal a consumir }\left(\tau_{f}\right) & 0,60 \\
\hline
\end{array}
$$

: Fonte: Vieira (1998). 